\title{
Design Fiction: Does the search for plausibility lead to deception?
}

\author{
Paul Coulton $^{\mathrm{a}^{*}}$, Joseph Lindley ${ }^{\mathrm{b}}$, Haider Ali Akmal ${ }^{\mathrm{a}}$ \\ amagination, Lancaster Institute for the Contemporary Arts, LICA Building, Lancaster University, UK, LA1 4YW. \\ ${ }^{\mathrm{b}}$ HighWire Doctoral Training Centre, LICA Building, Lancaster University, UK, LA1 4YW. \\ *Corresponding author: p.coulton@lancaster.ac.uk
}

\begin{abstract}
Since its inception the term 'design fiction' has generated considerable interest as a future-focused method of research through design whose aim is to suspend disbelief about change by depicting prototypes inside diegeses, or 'story worlds'. Plausibility is one of the key qualities often associated with suspension of disbelief, a quality encoded within the artefacts created as design fictions. In this paper we consider whether by crafting this plausibility, works of design fiction are inherently, or can become, deceptive. The notion of deception is potentially problematic for academic researchers who are bound by the research code of ethics at their particular institution and thus it is important to understand how plausibility and deception interact so as to understand any problems associated with using design fiction as a research method. We consider the plausibility of design fictions, looking at examples that are (1) obviously design fiction, (2) identified as design fiction, and (3) whose status is either ambiguous or concealed. We then explore the challenges involved in crafting plausibility by describing our experience of worldbuilding for a design fiction that explores the notion of empathic communications in a digital world. Our conclusions indicate that the form a design fiction takes, and preexisting familiarity with that form, is a key determinant for whether an audience mistake it for reality and are deceived. Furthermore we suggest that designers may become minded to deliberately employ deceitful strategies in order help their design fiction reach a larger audience,
\end{abstract}

Keywords: design fiction, plausibility, deception, design futures, speculative design

\section{Introduction}

Design fiction is a broad term that occupies a space among the wider miscellany of speculative design approaches. Speculative designs usually involve conceptual, future orientated, and critical prototypes. The factor that differentiates and distinguishes designs 
fiction from other speculative design is its novel use of world building to create what Huizinga described as a 'magic circle'. More specifically, this is "a place dedicated for the performance of an act apart" (Huizinga 1955), in design fiction the magic circle is a fictional world within which speculative prototypes, and their users, can plausibly co-exist. Julian Bleecker's ironically titled 'short essay on design, science, fact and fiction' (which is nearly 100 pages long) is probably the most influential single text on the topic. Bleecker brought together several notable ideas and pieces of research to formulate a cohesive story of what the then-nascent concept might really mean. In the essay Bleecker cites include David Kirby's research into how science informs and is represented in cinema, where the diegesis is the interior of any given story world (2010). Meanwhile Bruce Sterling is generally considered the originator of the term design fiction and provides the most widely cited definition of the practice: a suspension of disbelief about change that is achieved through the use of diegetic prototypes (Sterling 2013). Bleecker also draws on Dourish and Bell's influential paper (2014) that observes the crucial interplay between science fiction and ubiquitous computing research papers.

However, design fiction is arguably pre-paradigmatic and as the practice matures deeper questions around its nature accumulate (which is perhaps not surprising given the term was coined just a decade ago). One such question is about the Sterling definition's liberal use of the term diegesis, and how that pervades design fiction discourse. Debated by Aristotle and Plato, the concept of diegesis works harmoniously with Sterling's definition of design fiction, so long as diegesis's meaning is reduced to 'story world'. However when diegesis is considered in relation to its similarly ancient counterpart 'mimesis' then Sterling's widely cited definition appears flawed. Mimesis and diegesis are distinct and different ways of creating fictional worlds yet design fiction can clearly, and in a number of cases does, be both, hence a definition revolving around one and not the other is not holistic. Dissecting Sterling's well-cited definition is not central to the thesis of this paper itself, but instead raising this issue is intended to illustrate the accretion of foundational questions about the nature of design fiction. At this relatively early stage in the development of design fiction as a practice other fundamental questions about design fiction subsist: is design fiction distinct from critical design; are design fictions really about the present or the future; do historical precedents tell us that design speculations are valuable or meaningless; what is the precise nature of the relationship between 'research' and design fiction? Along with an increased interest in design fiction there is an increasingly substantial body of work to reflect upon and analyse, it is by reflecting on these works that we can begin to answer individual questions from the accumulated mass. It is through this reflective approach that this paper addresses one such question: does striving to build plausibility in to design fictions organically lead to deception?

\section{Design Fiction Plausibility}

Whilst even Sterling's frequently cited definition of design fiction is debatable, a key element in any design fiction that seems unequivocally relevant is the notion plausibility. Plausibility 
is an attribute that describes credibility and believability of a concept, as well as its potential to be a truth. From a design perspective, considering how to imbue speculative design concepts with plausibility is a significant challenge, given that plausibility is a subjective matter and is personal to each person engaging with a design fiction.

From an academic perspective while presenting a design fiction as credible and believable may be reasonable aspirations being deliberately deceptive and making fictions look like fact challenges what it is to undertake ethical research. There are precedents for acceptable deception within the context of some academic disciplines such as experimental psychology where it is deemed acceptable as long as the possible scientific, educational, or applied value justify the deception (Christensen 1988). Deception is commonly used within the Human Computer Interaction $(\mathrm{HCl})$ field in the form of the so-called Wizard of $\mathrm{Oz}$ technique. This is in reference to the 1939 Wizard of Oz movie starring Judy Garland in which the Wizard hides behind a curtain and used a voice amplifier and avatar projection to pretend to be 'The Great and Powerful $\mathrm{Oz}^{\prime}$. In a similar way $\mathrm{HCl}$ researchers surreptitiously intercept communications between participant and a computer system to supply the responses and actions, giving the appearance of a functional system, where in fact none exists. The purpose is normally to gauge user reactions. The deception in this case is deemed acceptable as their is generally negligible risk of harm comes to the participants (Goode 1996) and ultimately such deception is revealed.

Whilst a similar argument of justifiable deception could be used for applications of design fiction in academic contexts as they are unlikely to present any risk of harm to their audience, a worthy contribution to design fiction's discourse is a framework for considering how and if deception is deliberately built in to design fictions, or emerges from how they are presented. Laying tentative foundations for how such a framework might be put together, the following examples are placed on spectrum of presentation possibilities covering artefacts that are obviously design fiction, identified as design fiction, and those whose status is deliberately ambiguous or concealed. In the following sections we will explore why these labels are suitable and what properties design fictions in each category have in common with each other.

\subsection{Obviously Design Fiction}

These design fictions, no matter how plausible the subject matter, make signposts clearly visible to the audience. These signposts demonstrate clearly, even if not explicitly communicated then perhaps using the language of aesthetics, that by engaging with the work the audience is being invited to enter the magic circle. What is within the circle is a performance. It is 'other'. For example, in the design fiction video Uninvited Guests [//vimeo.com/128873380] created by design agency Superflux [superlux.in] for the ThingTank [thingtank.org] project, a number of design elements are adopted that appear to have been chosen to deliberately signify their fictional nature. The film presents the character Thomas, aged 70, who has lived alone since his wife died. The story premise is that 
his children have sent him a number of smart devices that allow them to track and monitor his diet, health and sleep from a distance. The devices are a fork, walking stick, pill container, and various sensors that both provide Thomas with feedback but also increasingly trigger messages from his family when he deviates from the rules imposed by the devices. Whilst all the smart devices are mundane in nature, in the film they represented by fluorescent 3D printed objects rather than more realistic artefacts. This deliberate choice is described by the designers as a way of representing the artefacts as "ghosts of the future" in which the form is unimportant in relation to their "monitoring, logging, tracking and processing of ambient feedback" (Superflux 2015). Along with the title of the video this serves to highlight the critical stance of the creators towards currents trends within the design of the Internet of Things, something that has been characterised by Evgeny Morozov as "'solutionism'- the idea that given the right code, algorithms and robots, technology can solve all of mankind's problems, effectively making life 'frictionless' and trouble-free" (Morozov 2012). Arguably this decision would characterise Uninvited Guests as Critical Design (Dunne 2008) rather than design fiction, but a discussion around the subtleties of such an academic distinction is outside the scope of this particular paper.

\subsection{Identified as Design Fiction}

In this category we consider design fictions whose designers overtly identify their work as a design fiction. The first example in this category is the video A Digital Tomorrow [//vimeo.com/48204264] developed by members of the Near Future Laboratory as part of the Curious Rituals project [//curiousrituals.wordpress.com/about/]. The aim of the project was to identify gestures, postures and rituals that have emerged with our use of digital technologies such as mobile phones, RFID cards etc. In the document produced for the project they highlight gestures such as 'The Periscope' (Nova, Miyake, Chiu, and Kwon 2012) whereby people hold their phone above their heads at events such as music concerts to record videos or take pictures. In addition to highlighting the gestures that are already observable they speculate about future gestures by extrapolating forward in time from contemporarily emerging technologies, such as face recognition. As with Uninvited Guests the film takes a slightly irreverent tone in that it is depicts these gestures and rituals outside the glossy and white-walled worlds that are the norm in the corporate 'vapour fiction' (Lindley 2015) videos that often promote new technologies. However, unlike Uninvited Guests the artefacts and systems represented are aesthetically mundane as are the environments in which the technology lives. The technologies does not always function correctly, a factor that resonates with our lived experiences. As such, certain elements have ambiguous quality whereby they might be considered real, particularly if the viewer is unfamiliar with the concept of design fictions.

The second example is a design fiction research paper, Game of Drones (Lindley and Coulton 2015). This is a curious format, and does not present the results of a design fiction experiment but rather the whole paper is a fictitious account of a research project that never happened. The paper describes a trial in which drones are used to provide services to local 
authorities, aiding in the enforcement of local by-laws. Specifically it presents a gamified system in which retired members of the police and armed services act as remote drone pilots helping to enforce by-laws relating to parking offences and dog fouling in a small UK city. The whole interaction takes place through a game-like interface and points are awarded for catching other citizens infringing upon the rules. The paper was submitted for The ACM SIGCHI Annual Symposium on Computer-Human Interaction in Play (CHI PLAY) 2015 in the 'Work in Progress' section. The paper indicates its fictional nature by including design fiction as a keyword at the start of the paper and revealing itself as a speculative artefact in the paper's conclusion. As authors of this paper we note that when the paper was reviewed the reviewers responses indicated that they had not fully grasped the fictitious nature of the paper and this was echoed by some of the reactions of other researchers when the work was presented at the conference (Lindley and Coulton 2016). Much of the confusion may be due to the fact the paper is written in the style of 'real' papers in this field. This perhaps suggests that unless the fiction is highlighted significantly within the artefact, our emotional engagement with the fictional world, especially if it resembles a familiar form, might override the signposts explicitly pointing out its fictional nature.

The paper now resides in the ACM digital library. Interestingly the automated classification system also struggles with the fictitious nature of the project (see Figure 1). The library's automated classification algorithm suggests the work is about robotic artificial intelligence and robotic systems relevant to government organisations. This highlights that the algorithm is susceptible to the plausibility of the Game of Drones fiction, inheriting the subjectivity of the humans that developed it.

One famous example of emotional engagement overriding logical reasoning, as previously discussed, is Orson Welles' contemporary retelling of H.G. Wells' War of Worlds in a radio programme on Sunday, October 30, 1938 which allegedly produced a wide scale panic amongst many of the show's listeners who believed it to be true. While not strictly design fiction, War of the Worlds is nonetheless a useful example of how an audience can be deceived. The reported numbers of people who believed the show was real is now disputed, but there were undoubtedly some who were enchanted by the way the story was presented. The first two thirds of the one-hour broadcast were presented as a series of simulated news bulletins, which suggested an actual alien invasion was currently in progress. Although popular mythology holds that a disclaimer was hastily added as the CBS executives became aware of the panic caused by the programme, in actual fact announcements describing the programme as a dramatisation of a work of fiction had always been planned and were made at at the beginning, before the middle break, after the middle break, and at the end of the broadcast. 
The ACM Computing Classification System (CCS rev.2012)

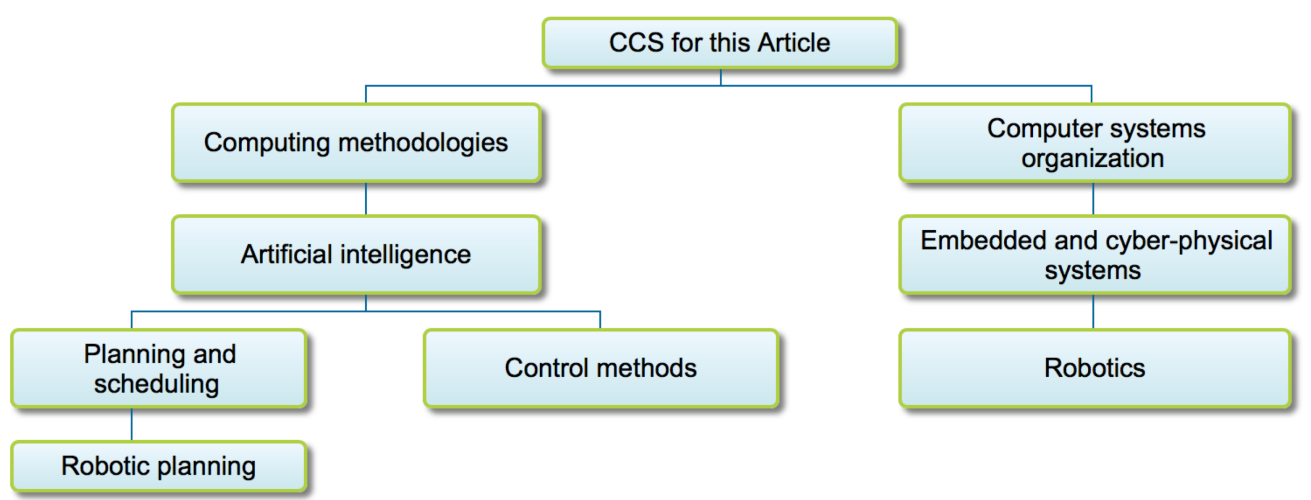

Note: Larger/Darker text within each node indicates a higher relevance of the materials to the taxonomic classification.

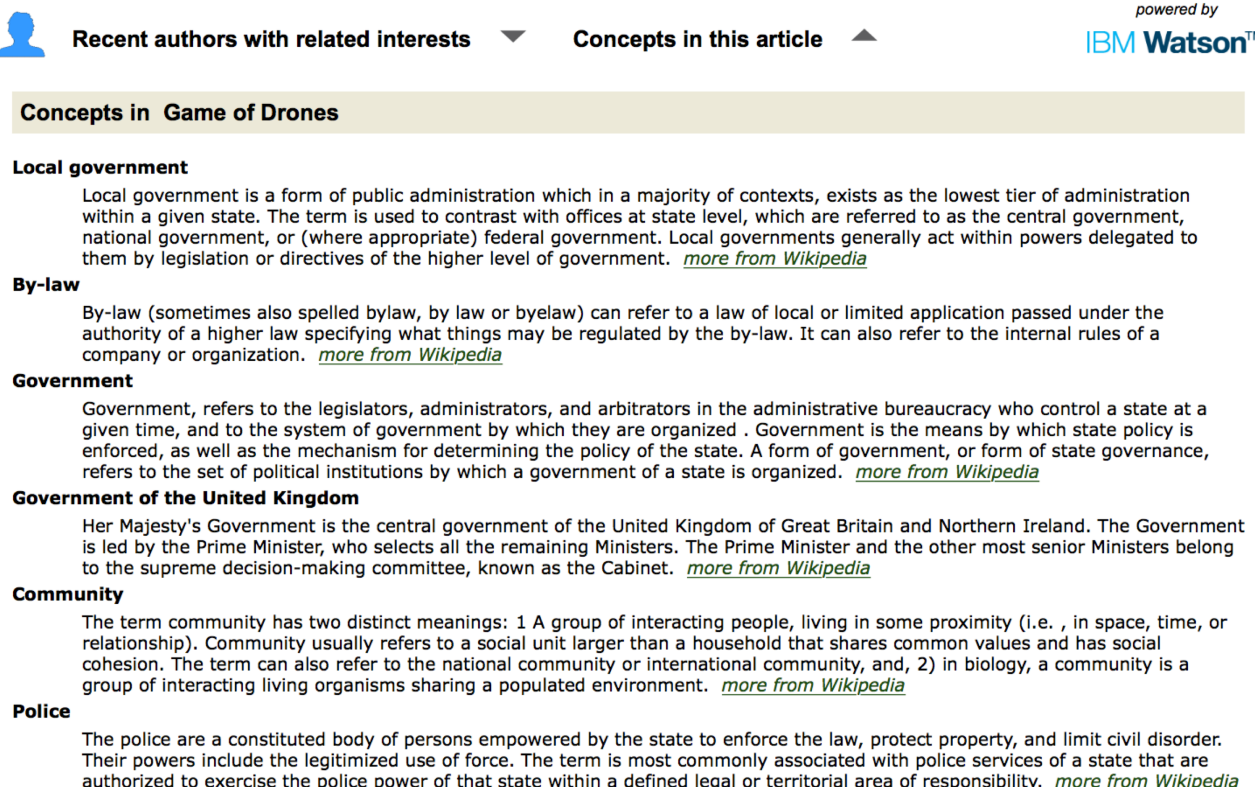

Government, refers to the legislators, administrators, and arbitrators in the administrative bureaucracy who control a state at a given time, and to the system of government by which they are organized. Government is the means by which state policy is enforced, as well as the mechanism for determining the policy of the state. A form of government, or form of state governance,

The police are a constituted body of persons empowered by the state to enforce the law, protect property, and limit civil disorder. Their powers include the legitimized use of force. The term is most commonly associated with police services of a state that are

Figure 1 Automated Document Classification for Design Fiction Paper Game of Drones

What this discussion highlights is that by creating plausible fictions audiences may end up being deceived, despite the efforts of the designer, and that the level of the deception is heavily influenced by the relationship between the format of the fiction, and the formats that the fiction's audience is familiar with. In each of these cases the boundary of the magic circle is clearly defined and communicated to the audience, however when the artefact is a pastiche of a familiar form, it seems audiences are sometimes incapable of discerning fact from fiction, or indeed fantasy.

\subsection{Ambiguous or Concealed Design Fiction}

The final category relates to concepts that do not reveal that they are design fictions or are deliberately ambiguous. The example we consider is Audio Tooth Implant by Loizeau and 
Auger. Whilst not originally identified as a design fiction by the designers we would argue it posses the attributes of design fiction in that it infers a world, not simply an artefact. The premise is that a miniature audio receiver can be implanted into a user's tooth during routine dental surgery. The tooth is coupled to a mobile phone which receives a long-range signal, the mobile phone then transmits a low frequency signal which energises the dormant receiver (in the tooth) by magnetic near field effects. A transducer then converts this signal into low amplitude vibrations that are received in the user's inner ear through bone transduction. The audio tooth implant was presented using a video [//vimeo.com/7485316] and demo model of a clear resin tooth with an electronic chip at its core at Future Products exhibition at the Science Museum in London in 2002. The video makes no mention of the speculative nature of the tooth design but instead is presented as promotional film from the Mibec corporation. The video dubs new audio over archive clips from old movies to highlight the features of the device. The video does not indicate to the viewer the fictitious nature of the tooth, and, as this format of the video has been regularly used in the advertising industry this presentation may actually make the video and the tooth concept seem more plausible.

The audio tooth implant received significant press coverage and while some reports indicated the tooth's purpose was actually "only supposed to help stimulate debate about future wearable computing devices" (BBC News 2002) the vast majority of reports presented it as a prototype intended for future production and ultimately it resulted in it being named by Time Magazine as one of the best inventions of 2002 (Time Magazine 2002). Whilst this misunderstanding could simply have been down to the plausible format in which the fiction was presented there was in fact a conscious decision by the two designers to be deceitful about their presentation of the tooth. In a 2006 interview with Wired Magazine 'Lying Through Their Teeth' the two designers explain this decision. Initially the press were not readily engaging with story and after a reporter had lost interest "after learning the implant was just an idea meant to stimulate conversation, not an actual invention" (Metz 2006) they decided maybe the needed to make it seem more 'real'. Therefore when the next reporter phoned they transitioned the tooth from conversation starter to prototypical product. They told the reporter that they "were looking to build a prototype, and, yes, possibly have it available within a year" (Metz 2006). All the coverage in the international mainstream media reporting resulted from this untruth. The designers said they had no qualms about manipulating the media as they didn't express much scepticism about the product and many details in the resulting articles were fabricated by the reporters. Whist this justification may be acceptable for artists or students (as the two designers were at the time of the hoax) it presents ethical challenges in other contexts.

In most cases cases design fictions are not deliberately deceptive, but rather the magic circle's boundary is indistinct. Misunderstandings and incorrectly interpreting a piece of design fiction as truth generally result from the format in which the design fiction is presented being familiar to the audience, this familiarity appears to lead to ambiguity. For most design fictions then, we must allow more than one interpretation. However, as the last example illustrates in the search for more plausibility (plausibility that may also lead to 
greater publicity) it may be tempting for designers to drift towards intentional deception. To understand how, when faced with this dilemma, designers deal with the challenge the following section describes our own experience of world building for a deliberately ambiguous design fiction.

\section{Crafting Design Fiction Plausibility}

As previously discussed design fictions are predominantly about creating plausible worlds in which particular artefacts would logically exist and whilst the previous case studies provide some insight, to quote Bruce Sterling "the best way to understand the many difficulties of design fiction is to attempt to create one" (Sterling 2014). Therefore in this section we consider the world building and subsequent artefacts created, within a research through design context (Frayling 1993, Gaver 2012). In this case it is a design fiction that explores the premise of empathic communications in a digital world: what if the Internet of Things could leverage empathy sensors?

In the research literature, empathy has yet to be completely understood; although studies thus far indicate the existence of three complementary, yet distinguishable, 'kinds' of empathy (Coulton, Huck, Hudson-Smith, Ralph, Mavros, Roberts, and Powell 2014):

1. Cognitive: The act of understanding how another person is feeling - but not necessarily also experiencing that particular feeling yourself.

2. Affective: Actually feeling the same feelings as another individual as a direct result of their affective state.

3. Compassionate: Feelings and/or expressions of concern and sympathy that are driven by empathy.

Whilst these descriptions provide us an understanding of how users might experience empathy, they provide little guidance for how we might identify when this experience occurs. In this research we draw from both fiction and science to build our plausible world in which empathy can be identified by computational means. The main fictional inspiration comes from the 1982 film Blade Runner, which is an adaptation of Philip K Dick's novel, Do Androids Dream of Electric Sheep (Dick, 1968). The film presents a vision of the future with flying cars and sophisticated artificial humans known as replicants (androids in the original novel). Whilst the technology presents a compelling vision of a possible future in a highly technological age, it poses the more fundamental question of what it means to be human in such a society. This is explored through one of the central elements of the film, a test known as Voight-Kampff, that measures bodily functions such as respiration, blush response, heart rate and eye movement, in response to emotionally provocative questions (Sammon, 1996). Replicants are unable to communicate the feeling of empathy for which these responses are indicative and, thus, are easily distinguished from humans by the Blade Runners. A physiological measurement of empathy was considered by Neumann and Westbury (2011) who identified eye movement, blinks, blood pressure, blood volume, electrodermal activity, 
and heart rate as possible correlates to empathy. Their work suggests that a real VoightKampff machine could be developed in the near future and provides a plausible scientific premise for the design fiction that is described the following sections.

\subsection{World Building - The Empathy SDK}

In the current age of digital development the most common way of allowing the creation of new products and services is through software and tools that would allow deployment across a range of platforms. Therefore the core of the design fiction world is the creation of the Digital Empathic Language (DEL) and associated Software Development Kit (SDK). An SDK allows developers and software designers to to utilise the core functions of programming languages such as the DEL. In doing so software developers can create new products and services. SDKs usually include a reference library detailing precisely what core functions are available to developers, so as part of the world building process for this design fiction a complete outline for the functionality, an overview of this is illustrated in Figure 2.

\section{DIGITAL EMPATHIC LANGUAGE (DEL) EMPATHY ENGINE SDK}
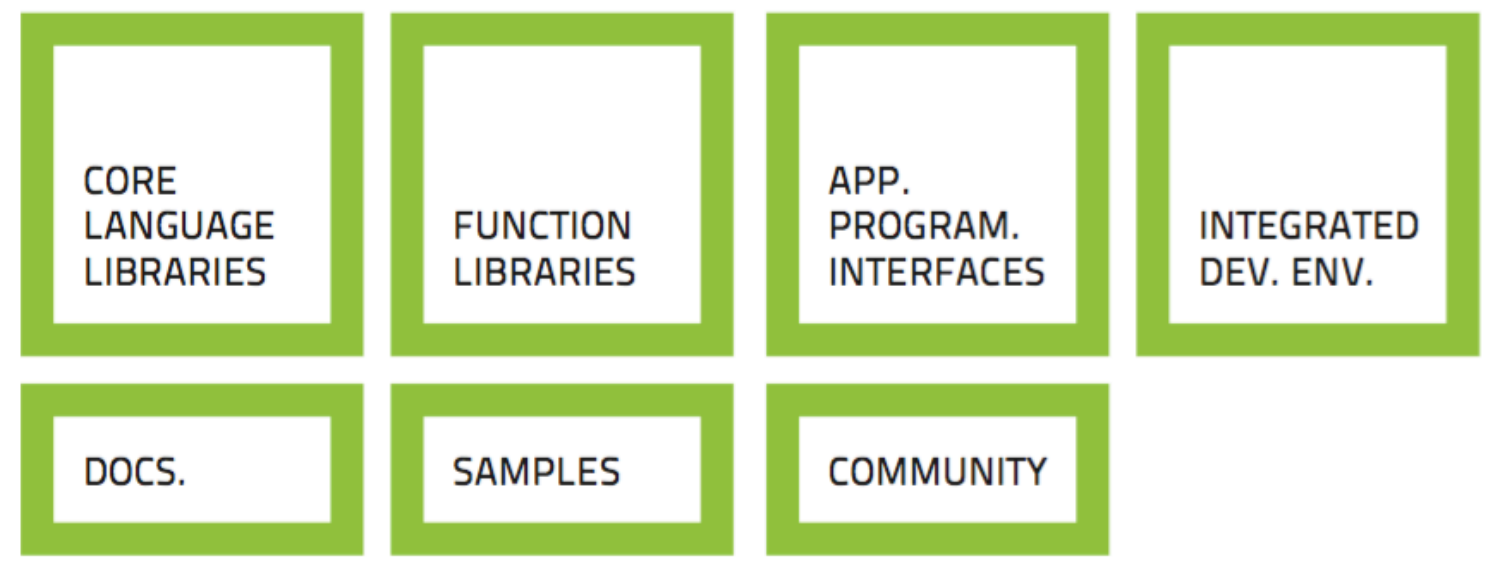

Figure 2 Overview of Empathy SDK Features

Having designed the platform through which all our empathy products and services could be created the question arises as how do we create plausibility for this platform, without actually developing it. In the past many startup companies developing new technical products would seek venture capital investment. In recent years crowdfunding has become commonplace, either through rewards based services such as KickStarter or Crowdfunder (that are effectively a pre-sales approach) or via equity based services such as the Syndicate Room or Crowdcube. It is arguable that all the products and services on KickStarter are 'fictional' until they are made tangible, first through reaching their funding goal but more importantly through successful research, development and production cycles after funding is achieved. Crowdfunding services such as Kickstarter typically require short videos to promote the proposed product or service, and in this instance we decided to adopt this form 
to present the DEL SDK design fiction. The video illustrated in Figure 3 presents a scenario where a team of computer scientists discuss the need for greater empathy online and how this could be achieved through with an empathy SDK. They describe a series of plausible scenarios and use cases to illustrate the empathy SDK's potential. The video does not highlight either that it is a design fiction or that the aim is develop a Kickstarter campaign.
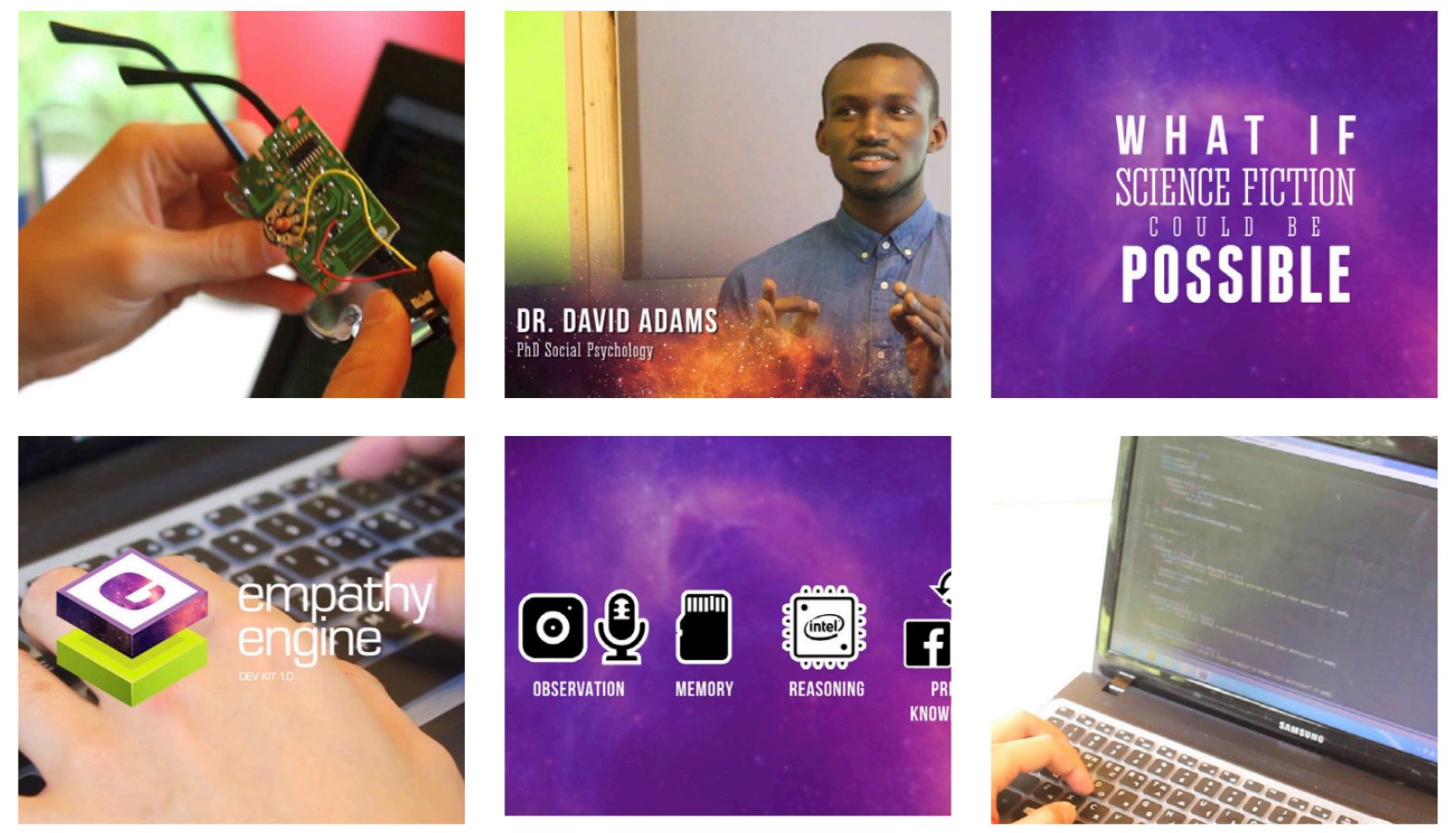

Figure 3 Collection of Screenshots from Empathy SDK Video

\subsection{Artefacts within the World : Voight-Kampff Machine and Doctor Patient Empathic Receiver}

Having created the design fiction world through the empathy SDK this world can be populated with more specific artefacts that make sense within that world.

The first example uses a medical scenario to present an application of the SDK capability within a wearable device. The device, to be worn by doctors, houses an earphone, camera and a processor. The device assists a doctor, when interacting with a patient, in gauging the emotional state of the patient. This information would be presented to the doctor through the earpiece and it was envisioned it could be used to as part of the training given to student doctors to improve the quality of their interactions with patients.

The product was designed as 3D model which was used to produce a technical manual for the apparatus with guidance on its usage (Figure 4). As with the SDK, care was taken to adopt a familiar aesthetic, in this case the produced manual is very similar to those included with smartphones, tablets, or other similar devices. 


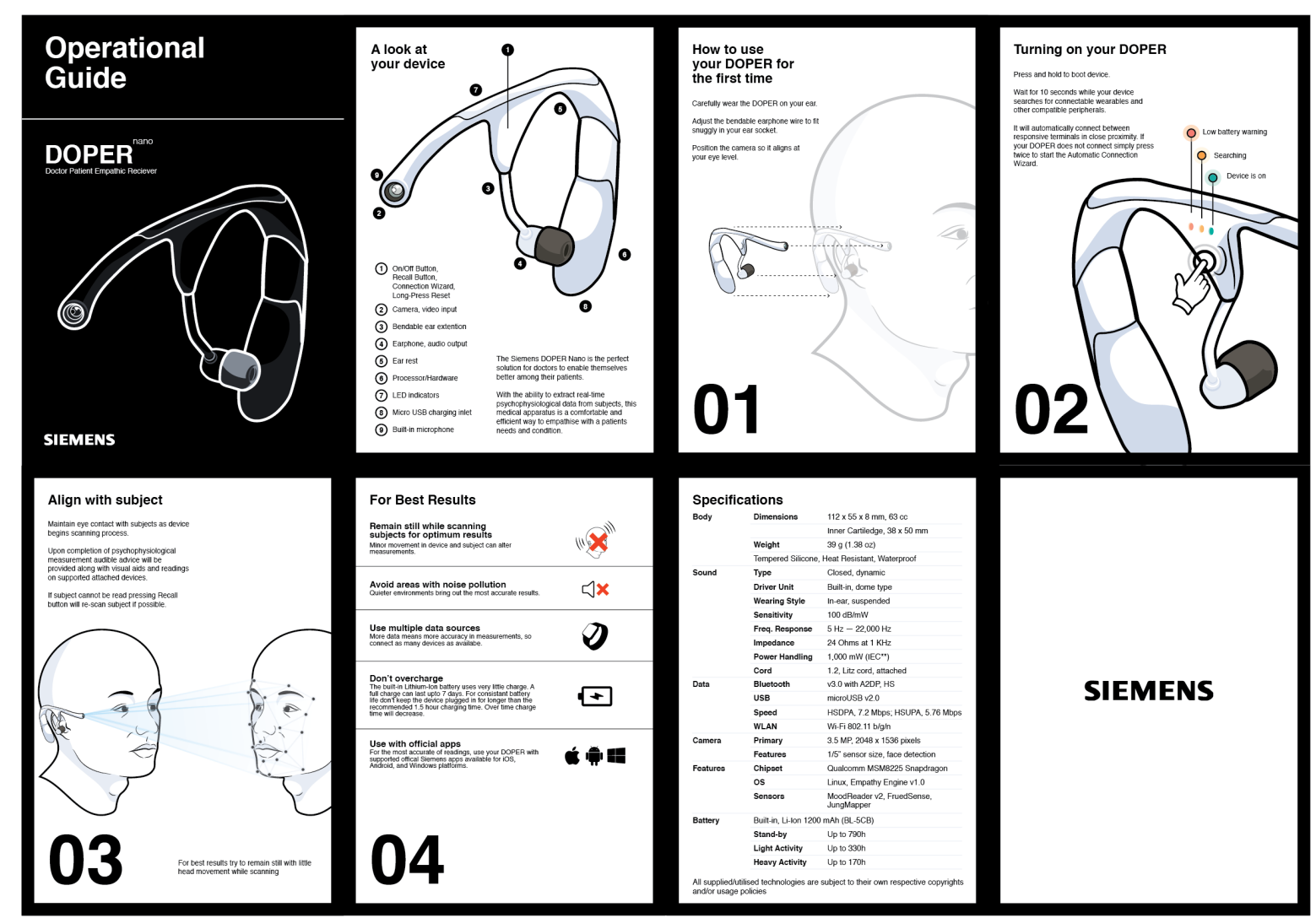

Figure 4 Doctor Patient Empathic Receiver User Guide

The second of artefacts deliberately references the Voight-Kampff machine from Philip K Dick's future world but imagines how we might present such a device so that it would be considered plausible today. In the film Blade Runner this design of the Voight-Kampff machine was a briefcase sized device which clearly echoed the computers or polygraph machines of 1982 when the film was made. Today phones and tablets are ubiquitous and it is more plausible to imagine an empathy-detecting device either within a smartphone or as a peripheral device to be used in conjunction with a smartphone. In terms of proposed useage, clearly using this device to detect rogue androids is not a plausible scenario, so we envisaged the device as a way of gauging empathic responses in online communications between individuals not known to each other, for example on online dating sites. A demo video was created to be associated with the Empathy SDK in order to highlight potential devices that will be built through the development of the SDK. The demo deliberately shows the system as a prototype using conventional laptops as stand-ins for the devices until the Kickstarter campaign enables their production. 

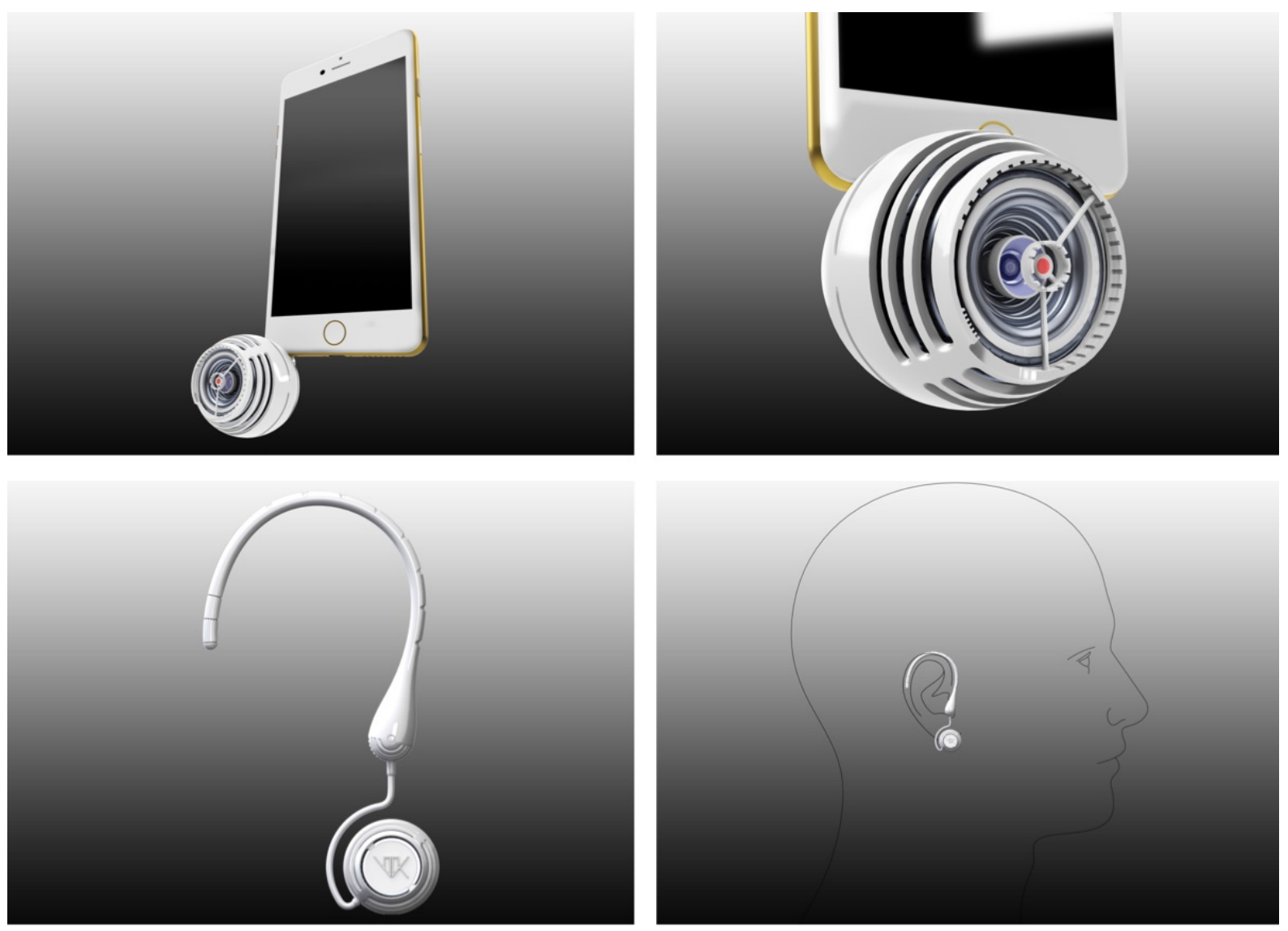

Figure 5 Proposed Voight-Kampff Machine Design to work with iPhone

\subsection{Evaluation}

Although we did consider setting up a fake KickStarter page to connect all the artefacts into a single story world we felt that this would be deliberately deceitful. Instead we merely linked the videos through social media channels with nothing to highlight the work as part of a design fiction, lending the work an ambiguous character. In total both videos have obtained over 1000 views although $90 \%$ of those being for the main empathy SDK which is not insignificant for a 5 minute video. The likely disparity between views is that the dating scenario only really makes sense in the world created through the empathy SDK. Whilst the videos attracted many positive comments and a press enquiry it was the email correspondence shown in Figure 6 that is most relevant to our previous discussion.

Whilst we wrote back and explained the fictional nature of the project, it took a considerable effort to convince the filmmaker that we had no intention of actually making the VoightKampff machine. This seems to support the earlier example of Loizeau and Auguer's Tooth Impact, that the journalists may be attracted to the story worlds created by design fiction, and it would be easy to try and garner publicity by creating a hoax that was only marginally more elaborate than this design fiction. 


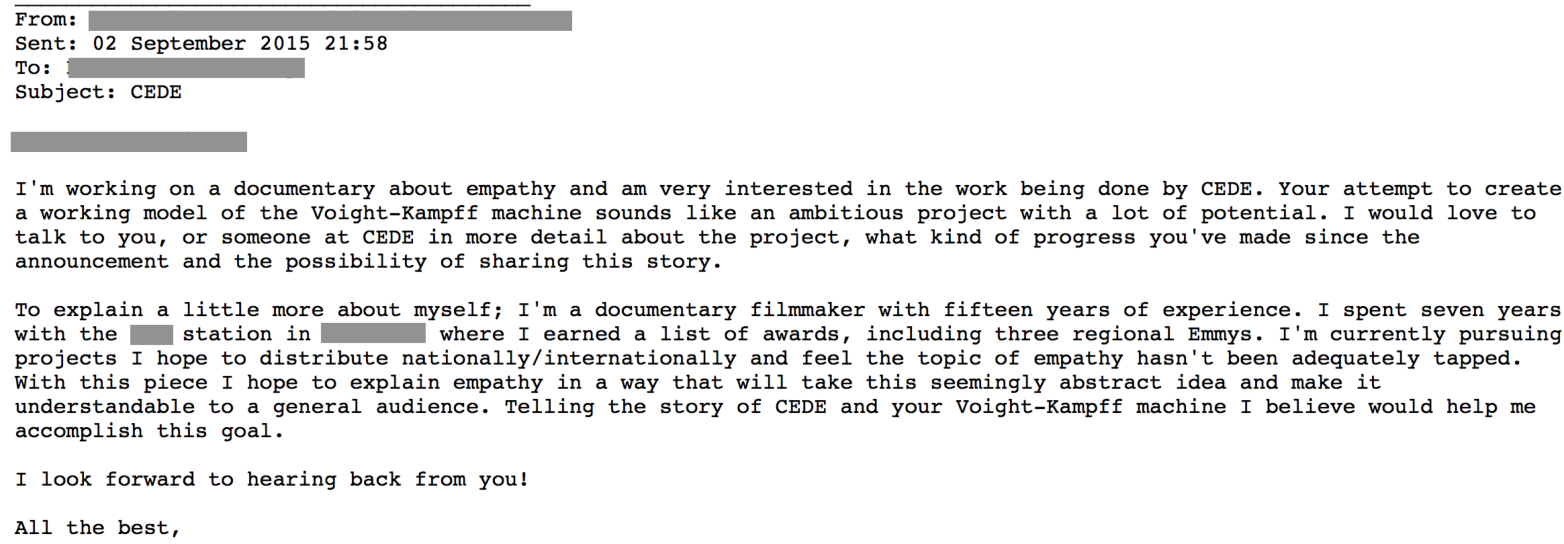

I'm working on a documentary about empathy and am very interested in the work being done by CEDE. Your attempt to create a working model of the Voight-Kampff machine sounds like an ambitious project with a lot of potential. I would love to talk to you, or someone at CEDE in more detail about the project, what kind of progress you've made since the announcement and the possibility of sharing this story.

To explain a little more about myself; I'm a documentary filmmaker with fifteen years of experience. I spent seven years with the station in where I earned a list of awards, including three regional Emms. I'm currently pursuing projects I hope to distribute nationally/internationally and feel the topic of empathy hasn't been adequately tapped. With this piece I hope to explain empathy in a way that will take this seemingly abstract idea and make it understandable to a general audience. Telling the story of CEDE and your Voight-Kampff machine I believe would help me accomplish this goal.

I look forward to hearing back from you!

All the best,

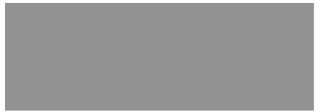

Figure 6 Email in regard Voight-Kampff Machine

\section{Conclusions}

In this paper we considered the plausibility of design fictions. Do well crafted design fictions tend towards plausibility, or is it the designers who intentionally deceive their audience to make their design fiction worlds appear real when in fact they are not? Like many techniques that plot current trajectories in order to utilise future visions as a means to reflect on our present, the ability of design fictions to perform as rhetorical tools is generally attributed to the plausibility of the worlds they present. If we consider dictionary meanings of plausible, it is synonymous with 'something that is not obviously untrue'. However, design fictions are, by definition, untruths. So, success design fictions strive to be 'not obviously untrue' while notwithstanding the fact that any design fiction's kernel is intentionally and fundamentally untrue. This contradiction creates tension, a tension stemming from a design fiction's intention to showcase unreal worlds in a manner that strives to appear real. The properties that can influence the relationships between these factors are at the behest of the speculative designer's crafting of any given design fiction world. Exploring how designers' decisions impact upon the ability of their creations to deceive is the purpose of this paper.

We can conclude with a concrete answer to the question asked in the paper's title: yes. The search for plausibility can (and frequently does) lead to deception. We can say this because of the strange contradiction between a design fiction's 'plausibility' (truth) and 'fiction' (untruth). Looked at from this angle however the question of design fiction is shoehorned into a 'non sequiturial' space by the paradoxical nature of the phrase 'plausible design fiction'. Perhaps the more intriguing part of the question we asked relates to the intentionality embodied within the word deceit. It seems that design fiction as a method tends toward deception, but that is a property of design fiction itself, and the only intrinsic intention behind that deceit comes from the decision to use design fiction in the first place. Beneath this fundamental property of design fiction though is another potential layer of 
intentional deceit coming from the autonomy of the designer and what choices they have taken about how to present their design fiction. We considered example presentations of design fictions and classify them as: obviously design fiction; identified as design fiction; and deliberately ambiguous design fictions. Through our examination of how the examples fit into these categories, as well as documenting our own experience of building a plausible design fiction world, we suggest that while instances of designers being deliberately deceptive are rare, well crafted design fictions can be very ambiguous even when purposefully signposted or explicitly described as design fiction by the designer. Driving the latent deception within any well crafted design fiction appears to be the familiarity of the format in which it is presented to its audience. While Marshall McLuhan famously said the 'medium is the message', we would argue that by transcending the designer's intentions and becoming entangled with the audience's assumptions and inclinations, in design fiction the format is the message. This is perhaps best described in metaphor by appropriating the duck test, "if it walks like a duck, quacks like a duck, then it probably is a duck"

[//en.wikipedia.org/wiki/Duck_test]. We would equate the 'metaphorical duck' to the format a design fiction adopts, and whether that format is depicted in a way that befits the content. For example, the algorithms and/or humans that come across the Game of Drones design fiction in the ACM digital library, may conclude that "it looks like a research paper, it is in the format of a research paper, so it probably is a research paper". Likewise the audience of the Empathy SDK's crowdfunding video may ask themselves "if it looks like a crowdfunding video, and it sounds like a crowdfunding video, then it probably is a crowdfunding video"..

Acknowledgements: We would like to thank the EPSRC for supporting the project Creating and Exploring Digital Empathy - Grant EP/L003635/1 and the HighWire Doctoral Training Centre - Grant EP/G037582/1 and the AHRC for supporting the project The Creative Exchange - Grant - AH/J005150/1. Special thanks to HighWire DTC student Mike Stead for producing the 3D model and images of the iPhone Voight-Kampff machine.

\section{References}

BBC News (2002). Put your mobile where your mouth is. http://news.bbc.co.uk/1/hi/sci/tech/2055654.stm last accessed 1/11/2015.

Bleecker, J., (2009). Design Fiction: A short essay on design, science, fact and fiction. Near Future Laboratory.

Coulton, P., Huck, J., Hudson-Smith, A., Ralph, B., Mavros, P., Roberts, J., \& Powell, P. (2014). Designing interactive systems to encourage empathy between users. In DIS Companion '14 Proceedings of the 2014 companion publication on Designing interactive systems. (pp. 13-16). New York: ACM. 10.1145/2598784.2602770

Christensen, L. (1988). Deception in Psychological Research When is its Use Justified?. Personality and Social Psychology Bulletin, 14(4), 664-675.

Dick, P.K (1968), Do Androids Dream of Electric Sheep, Doubleday.

Dourish, P. \& Bell, G., (2014). "Resistance is futile": reading science fiction alongside ubiquitous computing. Personal and Ubiquitous Computing, 18(4), pp.769-778. 
Dunne, A. (2008). Hertzian tales: Electronic products, aesthetic experience, and critical design, MIT Press.

Frayling, C. (1993). Research in art and design. Royal College of Art, Vol. 1 no. 1, 1-5.

Gaver, W. (2012). What should we expect from research through design?. In Proceedings of the SIGCHI conference on human factors in computing systems (pp. 937-946). ACM.

Goode, E. (1996). The ethics of deception in social research: A case study. Qualitative sociology, 19(1), 11-33.

Huizinga, J. (1955). Homo Ludens: A Study of the Play-element in Culture. Beacon Press.

Kirby, D., (2010). The Future is Now: Diegetic Prototypes and the Role of Popular Films in Generating Real-world Technological Development. Social Studies of Science, 40(1), pp.41-70.

Lindley, J., (2015). A pragmatics framework for design fiction. In Proceedings of the European Academy of Design Conference.

Lindley, J., and Coulton, P. (2015). Game of drones. In Proceedings of the 2015 Annual Symposium on Computer-Human Interaction in Play (pp. 613-618). ACM.

Lindley, J., \& Coulton, P. (2016). Pushing the limits of design fiction: the case for fictional research papers. In Proceedings of ACM conference on Human Factors in Computing Systems CHI2016. ACM.

Metz, R. (2006) Lying Through Their Teeth. Wired Magazine, http://www.wired.com/2006/04/lyingthrough-their-teeth/ last accessed 1/11/2015.

Morozov, E. (2012). The net delusion: The dark side of Internet freedom. PublicAffairs.

Neumann, D. L., \& Westbury, R. (2011). The psychophysiological measurement of empathy. Nova Science Publishers Inc.

Nova, N., Miyake, K., Chiu, W., \& Kwon, N. (2012) Curious Rituals: Gestural Interaction in the Digital Everyday, Near future laboratory .

Sammon, P. M. (1997). Future noir: the making of Blade Runner. IT Books.

Sterling, B. (2013). Patently untrue: fleshy defibrillators and synchronised baseball are changing the future. Wired Magazine,, http://www.wired.co.uk/magazine/archive/2013/10/play/patentlyuntrue, last accessed 17/12/2015.

Sterling, B. (2014). The Epic Struggle of the Internet of Things. Strelka Press.

Sturdee, M., Coulton, P., Lindley, J., Stead, M., Ali, H., \& Hudson-Smith, A. (2016). Design fiction: how to build a Voight Kampff machine. In Proceedings of ACM conference on Human Factors in Computing Systems CHI2016: altchi. ACM.

Superflux (2015). Uninvited Guests. http://www.superflux.in/work/uninvited-guests, last accessed $1 / 11 / 2015$.

Time Magazine (2002). Best Inventions of 2002. http://content.time.com/time/specials/packages/0,28757,1934259,00.html last accessed $1 / 11 / 2015$. 
About the Authors:

Paul Coulton is the Chair of Speculative and Game Design in the open and exploratory design-led research studio Imagination Lancaster. He uses a research through design approach for the speculative design of atoms and bits.

Joseph Lindley is a doctoral student researching design fiction at the HighWire Centre for Doctoral Training, Lancaster University.

Haider Ali Akmal recently completed an MA in Design, his dissertation is titled 'Empathy Engine: Research Through Design Fiction' at Lancaster University. 